\title{
Noncanonical repression of translation initiation through small RNA recruitment of the RNA chaperone Hfq
}

\author{
Guillaume Desnoyers and Eric Massé ${ }^{1}$ \\ RNA Group, Department of Biochemistry, University of Sherbrooke, Sherbrooke, Quebec J1H 5N4, Canada
}

The RNA chaperone Hfq is mostly known to help small regulatory RNAs (sRNAs) interact with target mRNAs to block initiating ribosomes. In this model, whereas the sRNA is directly competing with initiating $30 \mathrm{~S}$ ribosomal subunits, Hfq plays only an indirect role, allowing optimal sRNA-mRNA pairing. Here we report that Hfq is recruited by a SRNA, Spot42, to bind to a precise AU-rich region in the vicinity of the translation initiation region (TIR) of sdhC mRNA and competes directly with $30 \mathrm{~S}$ ribosomal subunits. We show that the sRNA Spot42 binds sdhC too far upstream of the TIR to directly repress translation initiation in vitro and in vivo. Contrary to the canonical model of sRNA regulation, this suggests a new mechanism where Hfq is directly involved in the translational repression of the target mRNA and where the sRNA acts only as a recruitment factor.

[Keywords: Spot42; Hfq; small RNA; translation initiation; noncanonical sRNA mechanism; translation block] Supplemental material is available for this article.

Received November 1, 2011; revised version accepted February 23, 2012.

Bacterial trans-encoded small RNAs (sRNAs) are a class of regulatory molecules that are widespread in Enterobacteriaceae species such as Escherichia coli and Salmonella sp. sRNAs are usually expressed in response to environmental stresses to maintain cell homeostasis (Waters and Storz 2009). A common feature among sRNAs is the requirement of the RNA chaperone Hfq for their activity (Vogel and Luisi 2011). This Sm-like RNA-binding protein was first discovered four decades ago as a host factor essential for bacteriophage $\mathrm{Q} \beta$ replication (Franze de Fernandez et al. 1968). In the last decade, elucidation of the role of Hfq in sRNA-mediated gene regulation has been an area of increasing interest. In most cases, sRNA-mediated regulation is decreased or abolished in a $\Delta h f q$ deletion strain (Zhang et al. 1998; Massé and Gottesman 2002; Moller et al. 2002a; ValentinHansen et al. 2004). Although Hfq is not thought to be directly involved in the repression of translation (Maki et al. 2008), it is critical for sRNA stability and has been shown to facilitate the pairing between sRNAs and their target mRNAs (Moller et al. 2002a; Geissmann and Touati 2004). Hfq is also known to interact with and recruit $\mathrm{RNase} \mathrm{E}$ to target mRNAs, allowing rapid and stoichiometric degradation of both sRNA and mRNA (Massé et al. 2003; Morita et al. 2005). The role of Hfq is not restricted to sRNA-mediated gene regulation.

${ }^{1}$ Corresponding author.

E-mail eric.masse@usherbrooke.ca.

Article is online at http://www.genesdev.org/cgi/doi/10.1101/gad.182493.111.
Indeed, Hfq has been reported to be a translational repressor that competes in vitro with initiating $30 \mathrm{~S}$ ribosomes for accessibility to the ribosome-binding site (RBS) on mRNA (Vytvytska et al. 2000). This behavior is explained by Hfq's preference to bind to AU-rich regions close to RBSs (Franze de Fernandez et al. 1972; Senear and Steitz 1976), which are known to act as translational enhancers (Zhang and Deutscher 1992; Hook-Barnard et al. 2007). In addition, Hfq is involved in RNA processing, as it regulates polyadenylation-dependent mRNA decay (Hajnsdorf and Regnier 2000; Mohanty et al. 2004).

One of the best-characterized Hfq-associated sRNAs is $\mathrm{RyhB}$, which is expressed under conditions of iron (Fe) starvation (Massé and Gottesman 2002) and regulates many mRNAs encoding nonessential Fe-using proteins. This post-transcriptional regulation allows the cell to preserve sufficient intracellular Fe for essential cellular functions (Massé et al. 2005; Jacques et al. 2006; Salvail et al. 2010). One of the first described targets of RyhB was the polycistronic mRNA sdhCDAB (Massé and Gottesman 2002), which encodes the four subunits of Fe-dependent succinate dehydrogenase of the tricarboxylic acid (TCA) cycle. Although the negative effect of RyhB on $s d h C D A B$ mRNA levels is clear, the direct interaction between both RNAs has not yet been demonstrated. Other examples of sRNAs interacting with Hfq include Spot42 (encoded by the spf gene), which responds to glucose availability (Moller et al. 2002b) and plays an important role in catabolic repression (Beisel and Storz 2011), and 
RybB, which is expressed following a membrane stress and is known to repress several outer membrane proteins (OMPs) (Johansen et al. 2006; Papenfort et al. 2006, 2010).

In general, sRNAs target the translation initiation region (TIR) of mRNAs by pairing with the Shine-Dalgarno (SD) sequence and/or the start codon, resulting in a direct competition with initiating $30 \mathrm{~S}$ ribosomal subunits. Because 30S initiating ribosomes are known to cover the region spanning nucleotide -20 to nucleotide +19 relative to the initiation codon (Beyer et al. 1994; Huttenhofer and Noller 1994), it is believed that sRNAs must pair within this window to inhibit translation. In recent years, however, many cases of translation-repressing sRNAs binding outside of this canonical region have been reported, involving a different mechanism in each case. For example, IstR-1, a Hfq-independent antisense RNA, has been shown to pair to a putative ribosome standby site located $\sim 100$ nucletotides (nt) upstream of the start codon of the tis $B$ mRNA to repress standby ribosomes (Darfeuille et al. 2007). Another example is GcvB sRNA, which targets C/A-rich regions in the $5^{\prime}$ untranslated region (UTR) of many mRNAs (Sharma et al. 2007). These C/A-rich regions are thought to act as translation enhancers. More recently, OmrA and OmrB sRNAs have been shown to repress $\operatorname{csg} D$ mRNA by targeting its $5^{\prime}$ UTR $>60 \mathrm{nt}$ upstream of the translation initiation codon. In this case, the mechanism is not fully understood but is known to involve a phylogenetically conserved RNA motif in the 5' UTR (Holmqvist et al. 2010). Furthermore, examples of sRNAs targeting the coding region to repress translation or destabilize mRNA have also been reported (Bouvier et al. 2008; Pfeiffer et al. 2009).

In this study, we addressed the regulation of the sdhCDAB mRNA by three sRNAs: Spot42, RyhB, and RybB. We present evidence that each one of the sRNAs paired at different regions within the $5^{\prime}$ UTR of $s d h C$ mRNA to repress the initiation of translation. Whereas both RyhB and RybB paired canonically at the TIR and recruited RNase E to actively degrade $s d h C D A B$ mRNA, Spot42 paired far upstream of TIR without promoting the rapid degradation of the mRNA. Surprisingly, affinity purification data clearly showed that Spot 42 pairing alone had no observable effect on mRNA in vivo, although it bound to $s d h C$ in the absence of Hfq. This result, combined with additional in vitro data, suggested that Spot 42 acted expressly to recruit Hfq at the TIR of $s d h C$ mRNA, which inhibits the binding of $30 \mathrm{~S}$ ribosomal subunits. We propose a novel mechanism where, contrary to the canonical model, the sRNA is not the main effector, but rather an intermediary factor for the recruitment of Hfq, which directly modulates translation initiation.

\section{Results}

Spot $42, R y h B$, and $R y b B$ regulate sdhC expression post-transcriptionally

We previously identified $s d h C D A B$ mRNA as a target of sRNA RyhB in E. coli (Massé and Gottesman 2002). One of the physiological outcomes of this regulation is the inability of strains overproducing RyhB to grow on a medium containing succinate as the sole carbon source. Notably, the same phenotype was also observed by another group in a bacterial strain overproducing sRNA Spot42 (Rice and Dahlberg 1982). In addition, a recent genomic study in Salmonella sp. has revealed that the expression of RybB sRNA led to a decrease in $s d h C D A B$ mRNA level (Papenfort et al. 2006). This result suggested that, in addition to RyhB, sRNAs Spot 42 and RybB could also be post-transcriptional regulators of the $s d h C D A B$ transcript.

Although RyhB, Spot42, and RybB may regulate $s d h C D A B$ mRNA expression, a direct pairing between these sRNAs and $s d h C D A B$ mRNA has not yet been reported. Using the bioinformatics tool TargetRNA (Tjaden et al. 2006), we found putative pairing sites for the three sRNAs in the 5' UTR region of $s d h C$ that corresponded to the first cistron of the mRNA. Whereas RyhB and RybB were predicted to pair at the SD sequence region, Spot 42 was predicted to pair $47 \mathrm{nt}$ upstream of the translational start codon of $s d h C$ (Fig. 1). Of note, one additional putative RyhB pairing site has also been predicted in the TIR of $s d h D$ (Massé and Gottesman 2002) but was not addressed in the present study.

To validate the regulation of $s d h C$ by RyhB, Spot42, and $\mathrm{RybB}$, we designed a translational reporter construct (termed $\mathrm{SdhC}_{258}$-LacZ) harboring the complete 5' UTR of $s d h C D A B$ mRNA (219 nt) and the first $39 \mathrm{nt}$ of the $s d h C$ ORF fused to the $\beta$-galactosidase-encoding $1 a c Z$ gene (see the Materials and Methods for details). Strains were constructed carrying the $\mathrm{SdhC}_{258}$ - $\mathrm{LacZ}$ fusion (inserted as a single copy in the chromosome) and harboring plasmids producing each sRNA from an arabinose-inducible promoter (termed pBAD-spf, pBAD-ryhB, and pBAD-rybB). Next, each sRNA was expressed individually, and $\beta$-galactosidase activity was monitored for $2 \mathrm{~h}$ following addition of arabinose (Fig. 2A). We observed that each sRNA was able to repress $\mathrm{SdhC}_{258}$-LacZ fusion expression, thus confirming that each one of the three sRNAs was a negative regulator of $s d h C$. We also tested the effect of the three sRNAs on a $s d h C$ transcriptional fusion (termed $s d h C_{258^{-}}$ lacZ) (Fig. 2B) in which the $\beta$-galactosidase gene harbored its own TIR. In this case, sRNAs expression had no effect on $\beta$-galactosidase activity, indicating that the effects observed on $\mathrm{SdhC}_{258}$-LacZ translational fusion were due to only translational repression and not a mRNA destabilization or a transcriptional repression. We also confirmed that none of the three sRNAs had an effect on the $s d h C$ promoter (Supplemental Fig. S1A).

We next investigated the effect of the three sRNAs on $\mathrm{SdhC}_{258}$-LacZ fusion regulation under physiological conditions. Because Spot42 is expressed in the presence of glucose (Moller et al. 2002b), we monitored $\mathrm{SdhC}_{258}$-LacZ fusion in wild-type and $\Delta s p f$ strains grown in M63glucose medium. Results showed a twofold increase in $\mathrm{SdhC}_{258}$-LacZ fusion activity in the $\Delta s p f$ strain as compared with the wild-type strain (Fig. 2C). An experiment was then carried out to study RyhB regulation. Wild-type and $\triangle r y h B$ strains were grown in M63-glucose medium in the absence of $\mathrm{Fe}$, as RyhB is highly expressed under these conditions (Desnoyers et al. 2009). Results showed a threefold increase in $\mathrm{SdhC}_{258}$-LacZ fusion activity in the $\Delta r y h B$ strain as compared with wild-type (Fig. 2C). RybB 


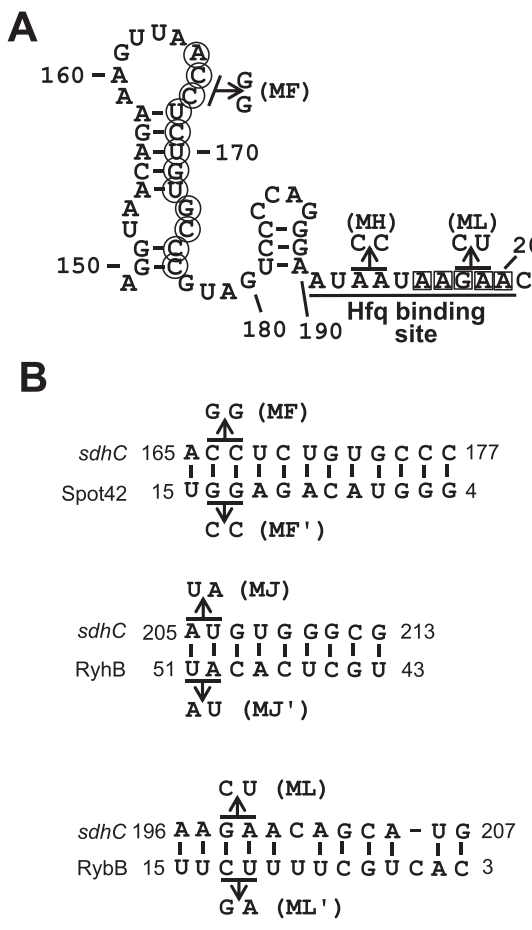

regulation was investigated with cells in the stationary phase, since RybB is mainly expressed under these conditions (Wassarman et al. 2001; Vogel et al. 2003; Johansen et al. 2006). Wild-type and $\Delta r y b B$ strains were grown in Luria-Bertani (LB) medium and monitored for expression of $\mathrm{SdhC}_{258}$-LacZ fusion during the late stationary phase. As expected, the RybB effect (1.8-fold) was observed only at $\mathrm{OD}_{600}>2.0$ (time $>300 \mathrm{~min}$ ). Also, as a control, we looked at the effect of knocking out the DsrA sRNA, which is not known to regulate $s d h C$ expression. Accordingly, we compared wild-type and $\triangle d s r A$ strains grown at $30^{\circ} \mathrm{C}$ in $\mathrm{LB}$ medium, a condition in which DsrA is expressed (Sledjeski et al. 1996). As seen in Supplemental Figure S1B, there is no significant difference in the expression of the $\mathrm{SdhC}_{258}$ - $\mathrm{LacZ}$ fusion between the two strains. Taken together, these results indicated that RyhB, Spot 42 , and $\mathrm{RybB}$ were all translational repressors of $s d h C$ mRNA.

Effects of Spot42, RyhB, and RybB on sdhCDAB mRNA levels in vivo

Translational repression by sRNAs is often associated with the recruitment of RNase $\mathrm{E}$ and a rapid degradation of the target mRNA (Massé et al. 2003). To determine whether RyhB, Spot 42 , and RybB promoted the rapid degradation of $s d h C D A B$ mRNA, we determined the levels of $s d h C D A B$ mRNA in a time-course manner following the expression of the three sRNAs. As shown in Figure 3A, the expression of both RyhB and RybB sRNA led to a very fast $1<2 \mathrm{~min}$ to $5 \mathrm{~min}$ ) decrease of $s d h C D A B$ mRNA levels, suggesting an active degradation of $s d h C D A B$. In marked contrast, the effect of Spot42 on $s d h C D A B$ mRNA was only observed 30 min after sRNA expression, suggesting that no RNase was actively recruited to promote mRNA degradation.
Figure 1. Putative pairing sites of Spot42, RyhB, and RybB sRNAs on the sdhC mRNA 5' UTR. (A) Schematic representation of the 5' UTR of $s d h C$. Nucleotides 1-148 are omitted from this representation. The secondary structure represented has been obtained by mfold (http://snowwhite.wellesley.edu/targetRNA/ index.html). Putative pairing sites for Spot42 (O), RyhB $(\bullet)$, RybB $(\square)$, and the Hfq-binding site are indicated. The Hfq-binding site mutant $(\mathrm{MH})$ is also indicated. $(B)$ Predicted pairing sites for Spot42, RyhB, and RybB on the sdhC 5' UTR. Pairing of RyhB and RybB sRNAs overlap the TIR of $s d h C$, while pairing of Spot42 is situated $48 \mathrm{nt}$ upstream of the start codon. Mutations used in Figure 4B are also indicated.
These differences in degradation kinetics could not be attributed to variation in sRNA induction kinetics (Supplemental Fig. S2), as all three sRNAs were expressed similarly.

To further investigate the potential role of RNase E and an RNA degradosome in sRNA-mediated degradation of sdhCDAB mRNA, we used a mutant (rne131) in which the scaffold region of RNase E required for the assembly of the RNA degradosome was absent (Leroy et al. 2002). This region of RNase $\mathrm{E}$ has also been shown to be essential for Hfq-dependent recruitment of RNase E for sRNAinduced mRNA decay (Ikeda et al. 2011). The results showed an absence of rapid degradation of $s d h C D A B$ mRNA following RyhB and RybB expression in the rne131 mutant (Fig. 3B) as compared with the wild-type strain (Fig. 3A). Remarkably, there was a striking similarity in mRNA turnover of $s d h C D A B$ whether Spot 42 was expressed in rne131 or wild-type backgrounds. Taken together, these results reinforced the notion that RNase E was recruited following both RyhB and RybB expression, but not Spot42, to rapidly degrade $s d h C D A B$ mRNA.

\section{Spot42 pairs with sdhC far upstream of the TIR}

We first carried out in-line probing using radiolabeled $s d h C$ RNA in the presence or absence of Spot42, RyhB, or RybB to verify in vitro the putative pairing sites suggested by bioinformatics data (Fig. 1). In-line probing exploits the natural ability of unstructured and unpaired nucleotides in RNA molecules to spontaneously cleave in solution (Regulski and Breaker 2008). The results showed that cleavage in $s d h C$ was significantly reduced from nucleotides A165 to C177 in the presence of Spot42 (Fig. 4A). A similar observation was made in the presence of RyhB, which afforded protection from nucleotides A205 to G213 

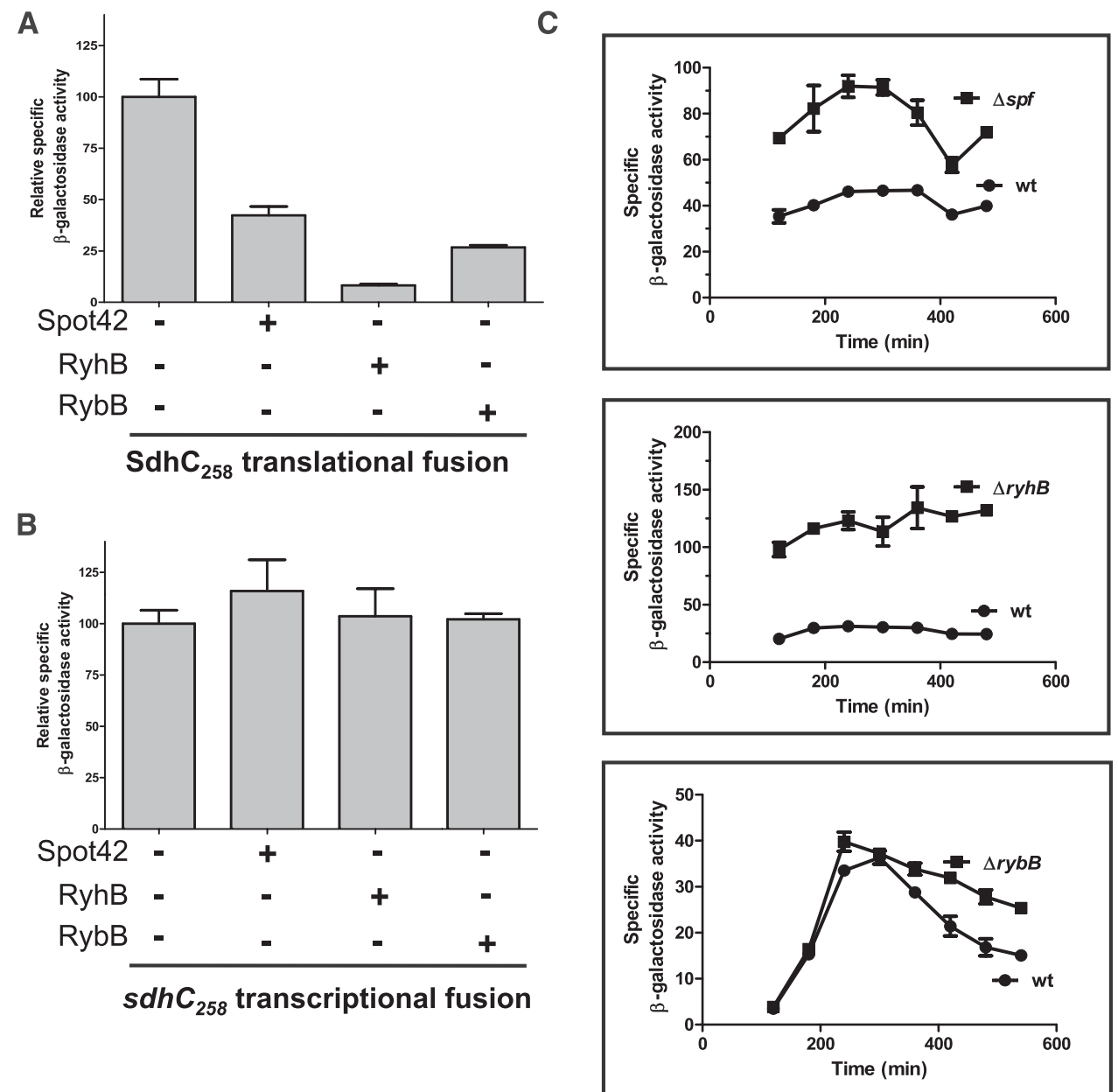

Figure 2. Spot42, RyhB, and RybB sRNAs post-transcriptionally regulate $s d h C$ mRNA. $\beta$-Galactosidase assays using $s d h C_{258}$-lacZ translational $(A)$ and transcriptional $(B)$ fusion were performed. Expression of each sRNA was individually induced at an $\mathrm{OD}_{600} \mathrm{Of}_{0.1}$, and specific $\beta$-galactosidase activity was measured $2 \mathrm{~h}$ later. The empty vector pNM12 was used as a control. $(C) \beta$-Galactosidase assays using $\mathrm{SdhC}_{258}$-LacZ translational fusion under conditions of natural expression of Spot42 (M63 glucose), RyhB (M63 glucose without $\mathrm{Fe})$, and RybB (LB). Wild-type strains are compared with the corresponding sRNA knockout strains.

and, RybB, which protected from nucleotides A196 to G208 (Fig. 4A). These results were consistent with in silico pairing data (Fig. 1).

In addition, we performed in vivo covariation mutagenesis using $\mathrm{SdhC}_{258}$ - $\mathrm{LacZ}$ translational fusion as a template. The three mutant constructs $\mathrm{SdhC}_{258} \mathrm{MF}-\mathrm{LacZ}$, $\mathrm{SdhC}_{258} \mathrm{MJ}$-LacZ, and $\mathrm{SdhC}_{258} \mathrm{ML}$-LacZ (illustrated in Fig. 1B) were designed to weaken the pairing with Spot42, RyhB, and RybB, respectively. Each one of these mutations reduced the repression activity of the corresponding sRNA (Fig. 4B). We also constructed mutants of Spot42, RyhB, and RybB harboring the compensatory mutations that restored the pairing with the mutant constructs $\mathrm{SdhC}_{258} \mathrm{MF}, \mathrm{SdhC}_{258} \mathrm{MJ}$, and $\mathrm{SdhC}_{258} \mathrm{ML}$. These mutants, called Spot42MF', RyhBMJ', and RybBML', were all able to fully, or at least significantly, restore wild-type regulation (Fig. 4B). Taken together, in vitro and in vivo data confirmed the in silico prediction that both RyhB and RybB bind to the TIR of $s d h C$ and that the Spot42-binding site was located far upstream of TIR.
Spot42, but not RyhB or RybB, fully depends on $H f q$ for repression of translation

Next, we addressed the question whether Spot42, RyhB, and RybB sRNAs were directly inhibiting $s d h C$ translation initiation. We used toeprinting assays that detect the formation of the $30 \mathrm{~S}$ translation initiation complex bound to mRNA. Results in Figure 5A showed that addition of purified $30 \mathrm{~S}$ ribosomal subunits and initiator tRNA (lane 8) to $s d h C$ mRNA created a strong block of reverse transcription $15 \mathrm{nt}$ downstream from the AUG codon. These observations were consistent with the formation of a translation initiation complex on mRNA. When increasing amounts of sRNAs Spot42, RyhB, RybB, or DsrA (used as a negative control) (Majdalani et al. 1998) were used, we observed that only RyhB and RybB were able to repress formation of the initiation complex (sRNA:sdhC ratio of 15:1) (Fig. 5A, lane 11). However, the addition of Spot42 or DsrA at even a 15-fold excess over $s d h C$ had no effect on the formation of the initiation complex (Fig. 5A, 


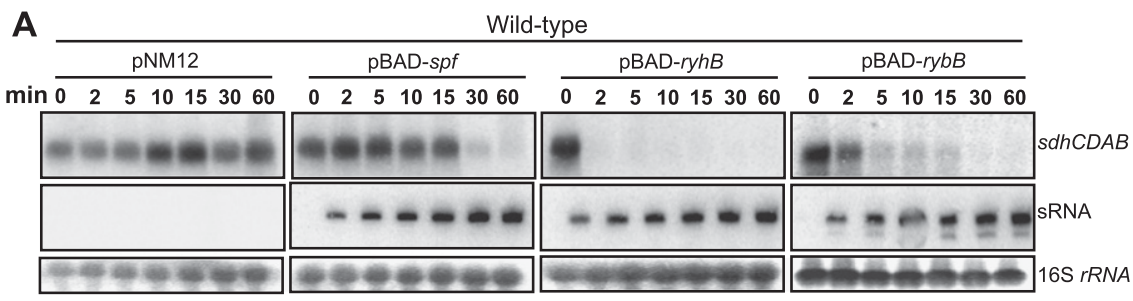

B

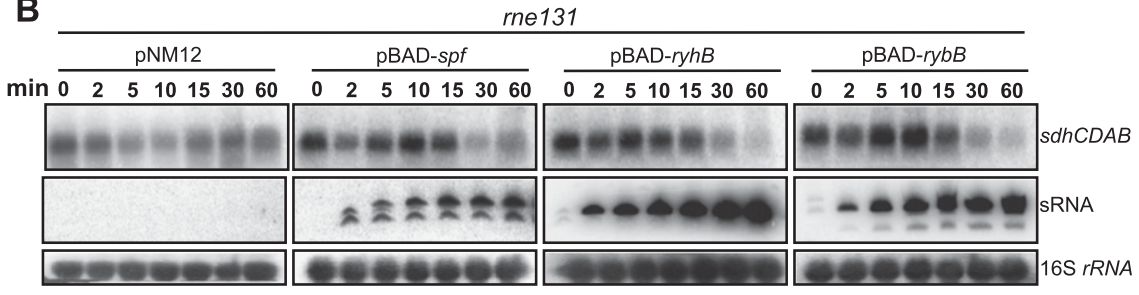

Figure 3. RyhB and RybB, but not Spot42, induce an active degradation of $s d h C D A B$ mRNA. Northern blots were performed on total RNA extracted from strain GD372 $(A)$ or GD527 (rne131 mutant) (B) harboring the indicated plasmids. Cells were grown on LB medium containing ampicillin to an $\mathrm{OD}_{600}$ of 0.5 , at which point arabinose was added at time 0 to induce sRNA expression. Total RNA was extracted at the indicated times. Probes complementary to $s d h C$, Spot42, RyhB, RybB, and 16S rRNA were used. The control plasmid (pNM12) panel was probed with all three sRNA probes. lane 11). As a control, we confirmed by performing PbAc probing (Supplemental Fig. S3) that at the same concentrations and in the same buffer as the toeprint experiment, Spot42 is able to pair to the $s d h C$ RNA in vitro. These results suggested that, contrary to RyhB and RybB, Spot 42 alone could not repress the initiation of translation of $s d h C$ even if it pairs to the region characterized in Figure 4.

We next examined the effect of Hfq under these experimental conditions. To address this, Hfq and $s d h C$ were mixed in a 1:1 ratio, and then we monitored the capacity of Spot42, RyhB, RybB, or DsrA to repress the formation of the translation initiation complex. Results showed that the presence of Hfq barely affected the binding of 30S ribosomal subunits (Fig. 5A, cf. lanes 8 and 13). As expected, the presence of Hfq increased the efficiency of RyhB- and RybB-mediated repression (Fig. 5A, lanes 13-16). Surprisingly, the presence of Hfq allowed Spot42 to significantly repress $30 \mathrm{~S}$ ribosomal subunit binding starting at a fivefold excess of Spot42 with respect to $s d h C$ (Fig. 5A, lane 15). However, DsrA was still unable to repress the formation of the initiation complex in the presence of Hfq. Together, these results provided evidence that Spot42 absolutely required $\mathrm{Hfq}$ to repress the binding of the $30 \mathrm{~S}$ ribosomal subunits to $s d h C$.

Next, we tested the effect of Hfq alone on the binding of $30 \mathrm{~S}$ ribosomal subunits to $s d h C$. As shown in Figure $5 \mathrm{~B}$, the addition of increasing amounts of Hfq led to partial inhibition of the translation initiation complex at a 2.5fold excess (lane 10) with respect to $s d h C$ mRNA and to a complete inhibition at a fivefold excess (lane 11). These in vitro results suggested that a moderately high molar ratio of $\mathrm{Hfq}$ was able to directly repress the binding of $30 \mathrm{~S}$ ribosomal subunits to $s d h C$ mRNA. This finding was in marked contrast to results shown in Figure 5A, where even high molar ratio (15-fold) of Spot42 alone could not repress $s d h C$.

\section{A Hfq-binding site on the 5' UTR of sdhC is essential for Spot42-induced repression of translation}

The results reported above indicated that, although Spot 42 could bind to $s d h C$ (Fig. 4A, lane 6), it was not able to affect
$30 \mathrm{~S}$ ribosomal subunit binding to $s d h C$ (Fig. 5A, lane 11), even at a high molar ratio (15:1). However, when Spot42 was in fivefold excess compared with $s d h C$, the presence of a stoichiometric amount of $\mathrm{Hfq}$ (5:1:1) efficiently repressed the binding of $30 \mathrm{~S}$ ribosomal subunits (Fig. 5A, lane 15). These results suggested that Hfq, with the help of Spot42, could bind directly and repress the translation of $s d h C$. If this possibility were true, one should be able to map a binding site of Hfq at, or close to, the TIR of the $s d h C 5^{\prime}$ UTR. A series of experiments were therefore carried out to investigate this possibility. We used in vitro chemical (lead acetate, which cleaves ssRNA) footprinting assays using radiolabeled $s d h C$ RNA and purified Hfq. The results showed that addition of $\mathrm{Hfq}$ at a 1:1 Hfq:sdhC ratio clearly protected $s d h C$ against cleavage from nucleotides A192-A201 (Fig. 6A, left panel). This region is highly AU-rich, consistent with previously described Hfq-binding sites (Franze de Fernandez et al 1972; Senear and Steitz 1976). It also fits a previously identified A-R-N motif that was shown to be preferentially bound by Hfq (Link et al. 2009). To validate the importance of this AUrich region for Hfq binding, we designed a $s d h C$ mutant that would prevent Hfq binding (termed sdhCMH) by replacing two adenine residues (A194-A195) by two cytosine residues (Fig. 1A). The results showed that addition of Hfq to $s d h C M H$ did not protect RNA from lead acetate cleavages, indicating that Hfq did not efficiently bind to sdhCMH (Fig. 6A).

We next tested the effect of Hfq binding to $s d h C$ in vivo by introducing the $\mathrm{MH}$ (mutated Hfq-binding site) mutation into the $\mathrm{SdhC}_{258}$-LacZ translational fusion, thus creating $\mathrm{SdhC}_{258} \mathrm{MH}-\mathrm{LacZ}$ fusion. The results showed the basal levels of translation for the $\mathrm{SdhC}_{258} \mathrm{MH}-\mathrm{LacZ}$ allele was decreased by a fourfold factor (Supplemental Fig. S4), suggesting that the AU-rich region recognized by Hfq had an important role in the translation activation of $s d h C$. We also tested the effect of each sRNA on $\mathrm{SdhC}_{258} \mathrm{MH}$-LacZ translational fusion. The results showed that RyhB and RybB were still able to repress $\mathrm{SdhC}_{258} \mathrm{MH}-$ LacZ fusion expression by a factor of at least twofold (Fig. 6B). In addition, we found that, even if Spot42 could potentially pair with $s d h C_{258} \mathrm{MH}$ RNA (Supplemental 
A

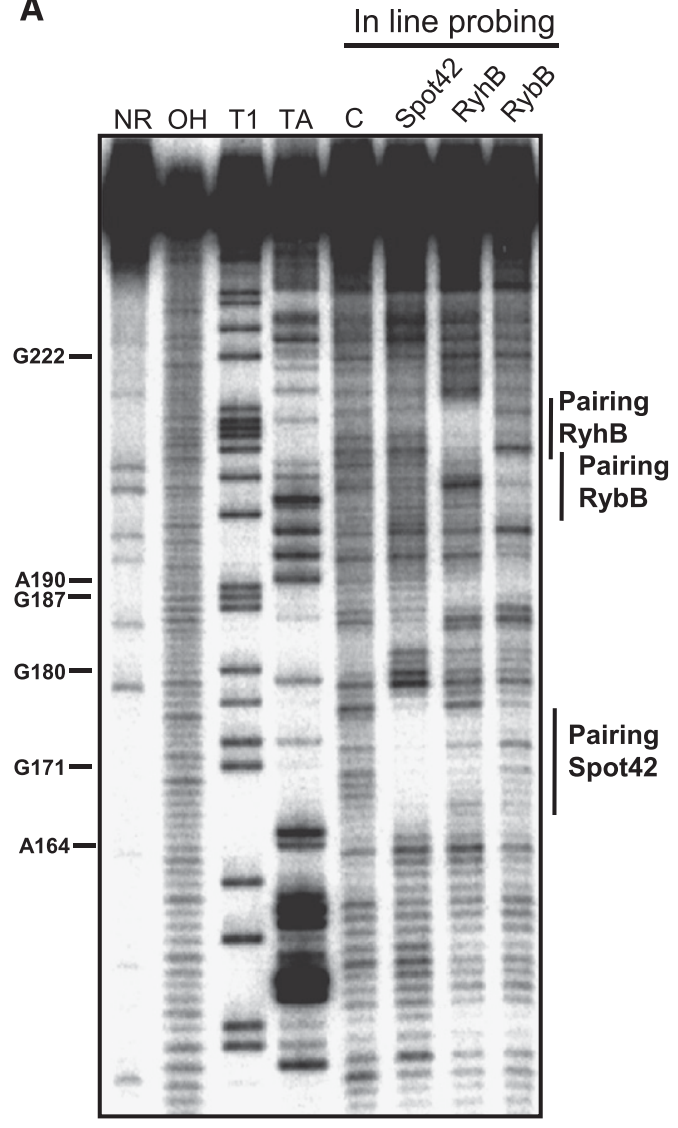

B
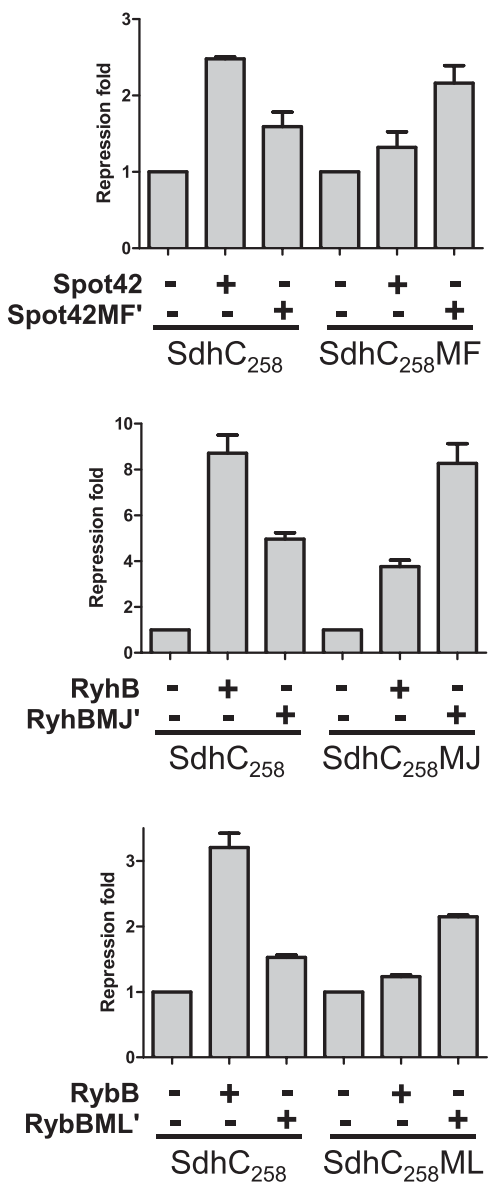

Figure 4. Analysis of Spot42, RyhB, and RybB pairing sites on $s d h C$ mRNA. $(A)$ In-line probing of the $5^{\prime}$-end-labeled $s d h C$ mRNA in the presence or absence of Spot42, RyhB, and RybB. The position of several G and A residues, relative to the transcriptional start, are indicated. (NR) Nonreacted control; (OH) alkaline ladder; (T1) RNase T1 ladder; (TA) RNase TA ladder. Except for the ladders, all experiments were carried out under native conditions. (B) Wild-type $\mathrm{SdhC}_{258}$-LacZ translational fusion is specifically repressed by wildtype Spot42, RyhB, and $\mathrm{RybB}$, whereas the mutated versions of the $\mathrm{SdhC}_{258}$-LacZ translational fusion are specifically repressed by the corresponding mutated sRNAs. See Figure 1B for a drawing of the mutations used in this panel. Expression of each sRNA (Spot42MF', RyhBMJ', and RybBML') was individually induced by the addition of arabinose at an $\mathrm{OD}_{600}$ of 0.1 , and specific $\beta$-galactosidase activity was measured $2 \mathrm{~h}$ later. The empty pNM12 was used as a control.

Fig. S5A), Spot42 had no effect on $\mathrm{SdhC}_{258} \mathrm{MH}-\mathrm{LacZ}$ fusion in vivo. This observation strongly suggested that the Hfqbinding site in the vicinity of the $s d h C$ TIR was essential for Spot42-mediated repression of translation. We also monitored the effect of all three sRNAs on the $\mathrm{SdhC}_{258^{-}}$ LacZ fusion in a $\Delta h f q$ background (Fig. 6B). In these experiments, RyhB was still able to strongly repress $s d h C$ translation, whereas RybB had a slight but reproducible negative effect on translation. Spot42 did not repress translation of $s d h C$ in the absence of Hfq. Of interest, basal expression levels of $\mathrm{SdhC}_{258}$-LacZ fusion in the $\Delta h f q$ background was slightly higher than the wild-type strain (Supplemental Fig. S4), further suggesting that Hfq acted as a translational repressor of $s d h C$ mRNA in vivo.

We next monitored the effect of Spot42, RyhB, and RybB on $s d h C D A B$ mRNA in the $\Delta h f q$ background. The results of Northern blot analysis revealed that RyhB and RybB had a moderate effect on mRNA degradation, whereas Spot42 had no effect (Supplemental Fig. S6).
Because Hfq is thought to recruit RNase $\mathrm{E}$ to a mRNA targeted by a sRNA (Morita et al. 2005; Ikeda et al. 2011), it was expected that each one of the three sRNAs had a reduced effect on mRNA levels in a $\Delta h f q$-null strain. However, the fact that RyhB and RybB were still able to induce degradation of $s d h C D A B$ mRNA, whereas Spot 42 was not, suggested an additional role for Hfq in the context of sRNA Spot42. Taken together, these results suggested that, in contrast to RyhB and RybB, Spot42 was unable to inhibit $s d h C$ expression in the absence of Hfq protein or the Hfq-binding site (nucleotides 191-200) on sdhC.

\section{Interchanging sRNA pairings sites also interchanges $H f q$ dependency}

Our data suggested that Spot42 binds to the 5' UTR too far upstream of the TIR to compete directly with $30 \mathrm{~S}$ ribosomal subunits. Therefore, it appeared likely that Spot42 used Hfq as a bridge to compete with initiating 
A

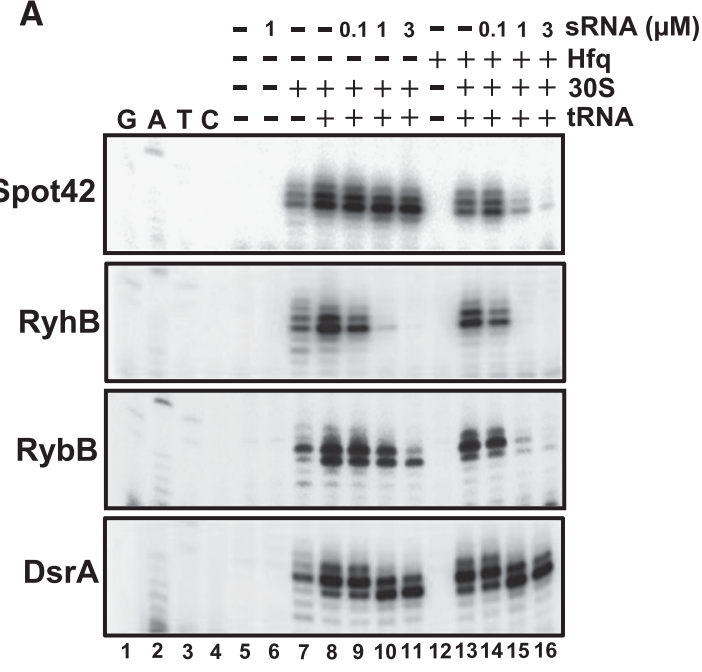

B

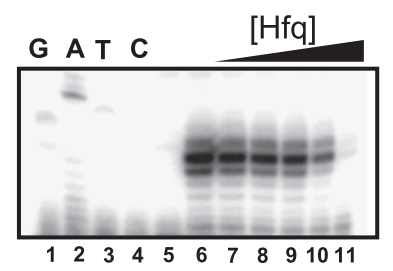

Figure 5. Repression of the $s d h C$ translation initiation complex formation by Spot42, RyhB, RybB, and Hfq. (A) Toeprint assay indicating that $\mathrm{RyhB}$ and $\mathrm{RybB}$ were able to prevent translation initiation complex formation in the absence of Hfq, whereas Spot42 was able to perform repression only in the presence of Hfq. The DsrA sRNA was used as a negative control. (B) Toeprint assay indicating that Hfq was able to prevent translation initiation complex formation on the $s d h C$ mRNA. Increasing amounts of Hfq were added $(0 \mu \mathrm{M}, 0.01 \mu \mathrm{M}, 0.1 \mu \mathrm{M}$, $0.2 \mu \mathrm{M}, 0.5 \mu \mathrm{M}$, and $1.0 \mu \mathrm{M})$. GATC refers to sequencing ladders generated with the same oligonucleotide (EM1262) used for toeprint.

ribosomes on the $s d h C$ TIR. This interpretation suggests that recruitment of $\mathrm{Hfq}$, regardless of the recruiting sRNA, should be sufficient to repress $s d h C$. To test this hypothesis, we interchanged the pairing sites of both Spot42 and RyhB sRNAs with $s d h C$. In this experimental design, the RyhB mutant (RyhBMS) would now pair at the original Spot42 pairing site far upstream of the RBS, and the Spot42 mutant (Spot42MR) would pair with the RBS of $s d h C$ (Supplemental Fig. S7). We first confirmed that both mutant sRNAs paired with the $s d h C 5^{\prime}$ UTR (Supplemental Fig. S5B) and then monitored their effects in vivo on $\mathrm{SdhC}_{258}$-LacZ fusion. The results showed that both Spot42MR and RyhBMS expressed from a pBAD promoter were able to repress $\mathrm{SdhC}_{258}$ - LacZ activity (Fig. 7A). Of significance, Spot42MR repressed translation to an extent similar to wild-type RyhB, and RyhBMS repressed as much as wild-type Spot42 (Fig. 7A). These data confirmed that direct pairing (by either Spot42MR or RyhB) to the TIR was more efficient than binding far upstream (such as RyhBMS and Spot42) to repress translation.
We next tested the importance of Hfq by analyzing the effect of Spot42MR and RyhBMS on mutant $\mathrm{SdhC}_{258} \mathrm{MH}-$ LacZ fusion and wild-type $\mathrm{SdhC}_{258}$-LacZ fusion in a $\Delta h f q$ background. The results showed that Spot42MR was still able to repress $\beta$-galactosidase activity in both cases, whereas RyhBMS had no effect regardless of the cellular backgrounds (Fig. 7A). We interpreted these data to suggest that Hfq binding to $s d h C$ was necessary for the RyhBMS mechanism, although this was not the case for the Spot $42 \mathrm{MR}$ repression mechanism of $s d h C$ translation.

We next studied the effect of both mutated sRNAsSpot42MR and RyhBMS - on $s d h C D A B$ mRNA levels in vivo. The results of Northern blot analysis showed that the expression of Spot42MR led to a rapid $(<5 \mathrm{~min})$ decrease in $s d h C D A B$ mRNA levels; RyhBMS required $>15$ min to reduce the mRNA levels (Fig. 7B). Interestingly, a comparison of the kinetics of mRNA decay between wild-type and mutant sRNAs revealed that both sRNAs pairing directly to the TIR (RyhB and Spot42MR) were acting very fast $(<5 \mathrm{~min})$, whereas both sRNAs pairing upstream of the TIR (Spot42 and RyhBMS) acted at a much slower rate $(>15 \mathrm{~min})$. These observations suggested that the sRNA pairing site may also have an effect on the $s d h C D A B$ mRNA's rate of decay. Furthermore, experiments using Spot 42 and RyhB probes confirmed that the two mutant sRNAs were expressed at levels comparable with wild-type sRNAs (data not shown).

A recent study has shown that the $3^{\prime}$-end poly-U tail of RyhB is essential for Hfq binding (Otaka et al. 2011). We took the opportunity of this finding to test whether the Hfq protein involved in translation repression is recruited by the sRNA. Accordingly, we constructed RyhB-LS4U and RyhBMS-LS4U sRNAs (shorter poly-U tails) (see Supplemental Fig. S7), which should have lost their abilities to bind $\mathrm{Hfq}$, and then tested the effect of these constructs on our translational $\mathrm{SdhC}_{258}$-LacZ fusion. Whereas the RyhBLS4U construct induced a 50\% decrease in the expression of $\mathrm{SdhC}_{258}$-LacZ, the RyhBMS-LS4U construct failed to repress the fusion (Fig. 7C). This suggested that, to repress translation of $s d h C$, the chaperone Hfq must be recruited by the poly-U tail of the sRNA binding at the upstream site of the TIR.

Next, we determined the in vivo capability of both the RyhB-LS4U and RyhBMS-LS4U constructs to bind to Hfq. To address this question, we developed an assay based on affinity purification of MS2 RNA stem-loop-tagged sRNA (see Supplemental Fig. S8A for a schematic view of the MS2tagged construct). This approach has been used successfully to demonstrate Hfq binding on MS2-tagged sRNAs (Said et al. 2009|. Each construct was cloned downstream from an arabinose-inducible promoter carried on a low-copy-number plasmid (see the Materials and Methods for details). After induction for $10 \mathrm{~min}$ with arabinose, total RNAs and proteins were extracted. As shown by Northern and Western blots (Fig. 7D, input), all RNAs of interest (RyhB, MS2RyhB, MS2-RyhB-LS4U, and MS2-RyhBMS-LS4U) as well as Hfq were detected before loading on the MS2 affinity column. Although they were expressed at lower levels than MS2-RyhB and MS2-RyhBMS, both the MS2-RyhBLS4U and MS2-RyhBMS-LS4U constructs were expressed 
A

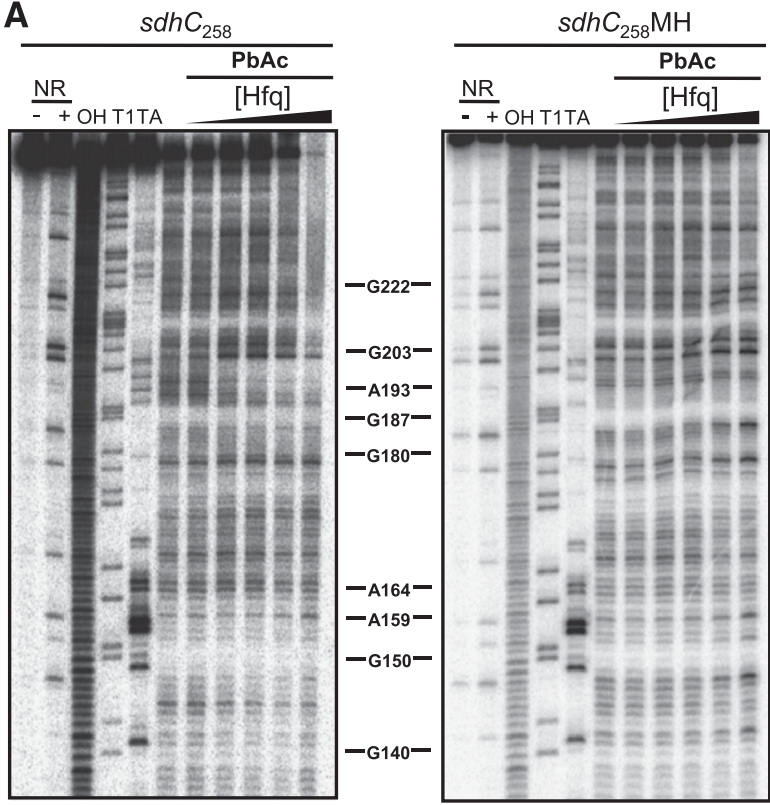

B

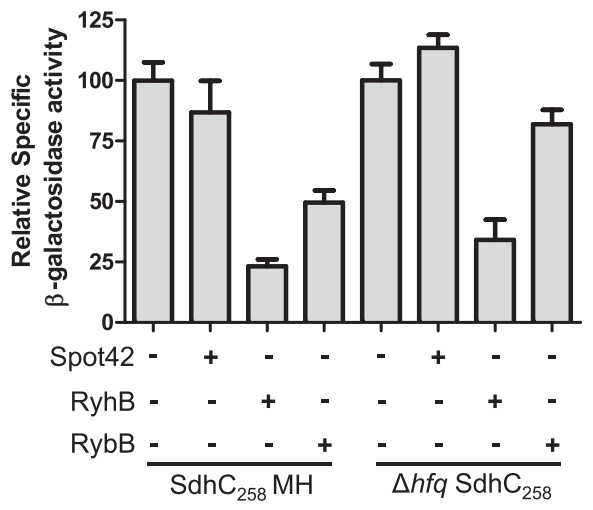

Figure 6. Hfq binding to $s d h C$ is essential for Spot42-mediated repression. $(A)$ Lead acetate probing of the $5^{\prime}$-end-labeled $s d h C$ or $s d h C M H$ mRNA in the presence of increasing amounts of $\mathrm{Hfq}(0 \mu \mathrm{M}, 0.01 \mu \mathrm{M}, 0.1 \mu \mathrm{M}, 0.2 \mu \mathrm{M}, 0.5 \mu \mathrm{M}$, and $1.0 \mu \mathrm{M})$. The $s d h C M H$ mutation is pictured in Figure 1A. Nonreacted controls were performed in the absence $(-)$ or presence $(+)$ of $1 \mu \mathrm{M}$ Hfq. The position of several G and A residues, relative to the transcriptional start, are given. (NR) Nonreacted control; (OH) alkaline ladder; (T1) RNase T1 ladder; (TA) RNase TA ladder; (PbAc) lead acetate. Except for the ladders, all experiments were carried out under native conditions. (B) $\beta$-Galactosidase assays with $\mathrm{SdhC}_{258} \mathrm{MH}$-LacZ or $\mathrm{SdhC}_{258}$-LacZ translational fusion in wild-type or $\Delta h f q$ strains. Expression of each sRNA (pBAD-spot42, pBAD-ryhB, or pBAD-rybB) was individually induced by the addition of arabinose at an $\mathrm{OD}_{600} \mathrm{Of}_{0.1}$, and specific $\beta$-galactosidase activity was measured $2 \mathrm{~h}$ later. The empty vector pNM12 was used as a control.

at comparable levels before purification (Fig. 7D, lanes $3,4)$.

After purification of the cellular extracts, the constructs MS2-RyhB and MS2-RyhBMS strongly bound to the Hfq chaperone, as expected (Fig. 7D, lane 7). In contrast, both the MS2-tagged RyhB-LS4U and RyhBMS-LS4U constructs have lost their ability to strongly bind Hfq in vivo (Fig. 7D, lanes 7,8). Together with the results in Figure $7 \mathrm{C}$, this strongly suggests that sRNA constructs pairing upstream of the RBS region must bind directly to the Hfq protein for translation repression of $s d h C$.

\section{Spot42 pairing on sdhC catalyzes the recruitment} of $\mathrm{Hfq}$ in vivo

Our results indicated that Spot 42 was fully dependent on Hfq to repress $s d h C$ translation. Thus, we asked whether Spot42 was able to promote the recruitment of Hfq to the $5^{\prime}$ UTR of $s d h C$ mRNA in vivo. We designed an approach based on affinity purification of the $s d h C$ transcript tagged with a MS2 RNA stem-loop (see Supplemental Fig. S8B for a schematic view of the construct). A plasmid (termed pFR $\Delta$-sdh $C_{258}$-MS2) harboring the promoter, the $5^{\prime}$ UTR of $s d h C D A B$ mRNA, and the first $39 \mathrm{nt}$ of the $s d h C$ ORF fused to the MS2 RNA stem-loops (see the Materials and Methods for details) was engineered for that purpose. As controls, we included a vector expressing the MS2 tag only and a second vector expressing the $s d h C_{258}$ transcript only, both under the control of the $s d h C D A B$ promoter. Strains carrying pFR $\Delta$-s $d h C_{258}$-MS2, pFR $\Delta$-MS2, or pFR $\Delta$-s $d h C_{258}$ plasmids and arabinose-inducible pGD3-spf or the empty pGD3 vector were treated with arabinose for $20 \mathrm{~min}$ before total RNAs and proteins were extracted. As shown by Northern and Western blots (Fig. 8A, input), all RNAs of interest $\left(s d h C_{258}\right.$-MS2, MS2, and $\left.s d h C_{258}\right)$ as well as Hfq were detected before loading on the MS2 affinity column. Next, we performed affinity purification of $s d h C_{258}$-MS2, MS2, and $s d h C_{258}$ by loading the cellular lysate on the MS2 affinity column. Total RNAs and proteins were collected and analyzed by Northern and Western blots. The results showed that equal amounts of the $s d h C_{258^{-}}$ MS2 construct were retrieved whether Spot 42 was absent or expressed (Fig. 8A, lanes 9,10, output). However, we noted that Spot 42 was recovered exclusively from the strain expressing $s d h C_{258}$-MS2 (Fig. 8A, lane 10) and not from strains expressing either MS2 (Fig. 8A, lane 14) or $s d h C_{258}$ (Fig. 8A, lane 16) only. These experiments confirmed that sRNA Spot42 paired with $s d h C 5^{\prime}$ UTR RNA in vivo. Importantly, expression of Spot 42 correlated with a 2.6-fold increase in the Hfq signal (Fig. 8A [cf. lanes 9 and 10, Western blots], C [densitometry]). There was no recovery of Hfq from strains expressing the MS2 or $s d h C_{258}$ constructs (Fig. 8A, lanes 13-16).

We next inserted the $\mathrm{MH}$ mutation in the $s d h C_{258}$-MS2 construct to generate the pFR $\Delta-s d h C_{258} \mathrm{MH}-\mathrm{MS} 2$ plasmid. After performing affinity purification, we observed considerably less $(50 \%) \mathrm{Hfq}$ protein recovered from $s d h \mathrm{C}_{258} \mathrm{MH}$ MS2 RNA as compared with the wild-type $s d h C_{258}$-MS2 
A
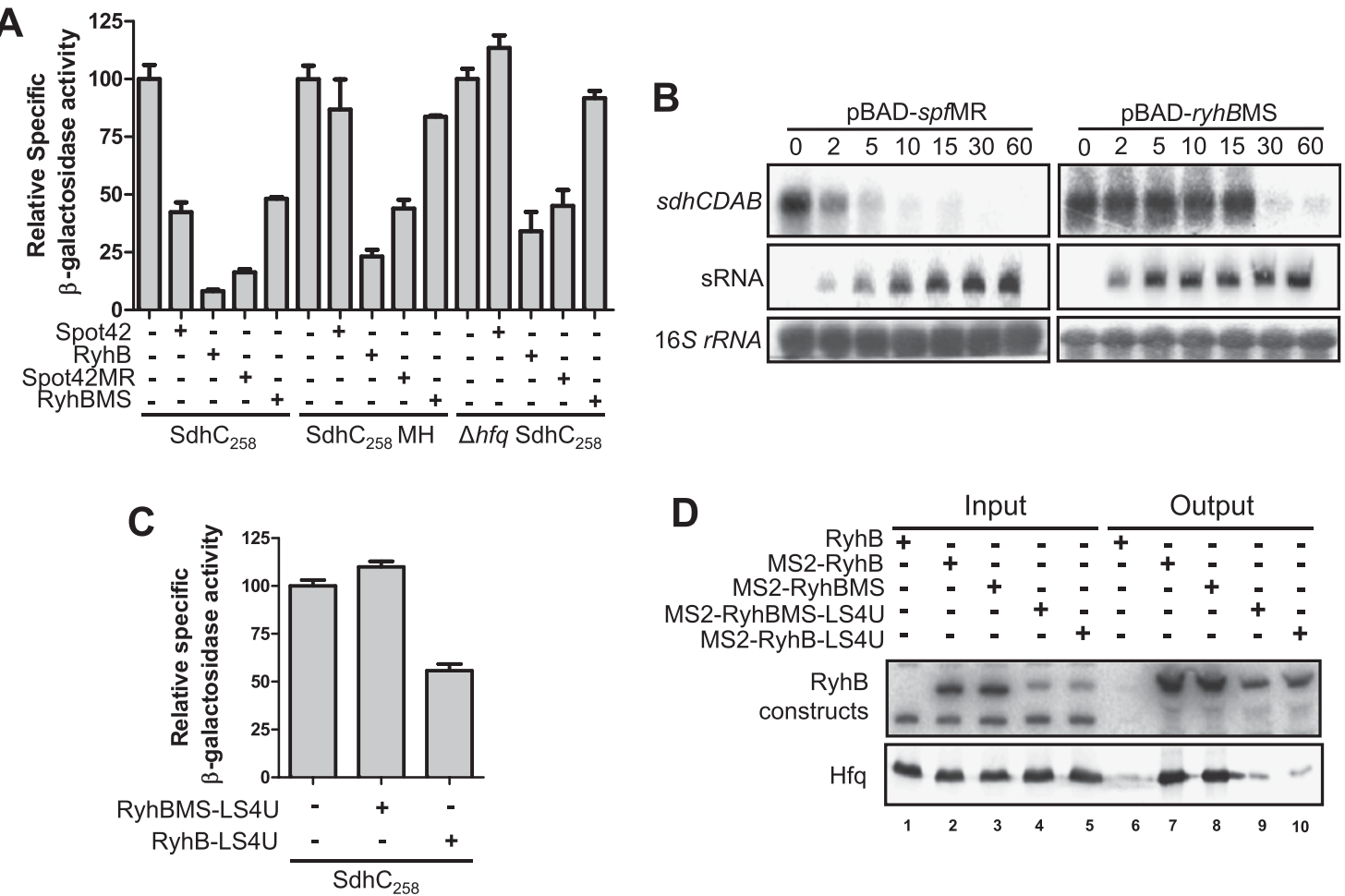

Figure 7. Effect of interchanging Spot42 and RyhB pairing sites on the $s d h C$ mRNA. (A) $\beta$-Galactosidase assays with SdhC 258 -LacZ or $\mathrm{SdhC}_{258} \mathrm{MH}$-LacZ translational fusions in wild-type and $\Delta h f q$ strains. Expression of each sRNA (pBAD-spot42MR or pBAD-ryhBMS) was individually induced by the addition of arabinose at an $\mathrm{OD}_{600}$ of 0.1 , and specific $\beta$-galactosidase activity was measured $2 \mathrm{~h}$ later. The plasmid pNM12 was used as a control. $(B)$ Northern blot analysis of total RNA extracted from triple-knockout $\Delta s p f / \Delta r y h B / \Delta r y b B$ strains harboring the indicated plasmids, hybridized with $s d h C$ - and sRNA-specific probes. Cells were grown on LB medium in the presence of ampicillin to an $\mathrm{OD}_{600}$ of 0.5 , at which point arabinose was added at time 0 to induce sRNA expression. Total RNA was extracted at indicated times. $16 \mathrm{~S}$ rRNA was used as a loading control. (C) $\beta$-Galactosidase assay using $\mathrm{SdhC}_{258}$-LacZ translational fusion. sRNA mutated for their Hfq-binding sites (LS4U; poly-U tail shortened) were individually induced by the addition of arabinose at an $\mathrm{OD}_{600}$ of 0.1 , and specific $\beta$-galactosidase activity was measured $2 \mathrm{~h}$ later. The empty pNM12 was used as a control. $(D)$ Affinity purification from strains expressing different RyhB variants. Cells were grown in LB medium in the presence of ampicillin to an $\mathrm{OD}_{600}$ of 0.5 , at which point arabinose was added at time 0 to induce sRNA expression. Total RNA was extracted 10 min later. Northern blots (RyhB probe) and Western blots (Hfq antibody) were performed on samples taken before (input) and after (output) affinity purification.

construct (Fig. 8A, output, cf. lanes 9 and 11). These findings corroborated in vitro results (Fig. 6A) and strongly suggested that the Hfq-binding site on $s d h C$ was functional in vivo. Interestingly, expression of Spot42 also led to a small but reproducible Hfq recovery in the case of $s d h C_{258}$ MH-MS2 RNA (Fig. 8A, cf. lanes 11 and 12). In addition, Spot42 sRNA was also retrieved to a level comparable with the pFR $\Delta$-sdh $C_{258}$-MS2 construct (Fig. 8A, cf. lanes 10 and 12), indicating that the Hfq-binding site mutation on the $s d h C 5^{\prime}$ UTR did not interfere with the pairing with Spot 42 and that the results of Figure $6 \mathrm{~B}$ were not due to a reduced sRNA binding.

We also inserted the MF (mutated Spot42 pairing site) mutation in the $s d h C_{258}$-MS2 construct and performed affinity purification with a pFR $\Delta-s d h C_{258}$ MF-MS2 plasmid. As shown in Figure 8C, disruption of Spot42 pairing with $s d h C_{258} \mathrm{MF}$ prevents Hfq recruitment. This confirms that pairing of Spot 42 to $s d h C$ mRNA is essential for the recruitment of Hfq. Finally, we performed affinity purification in $\Delta h f q$ cells carrying the pFR $\Delta$-s $d h C_{258}$-MS2 plasmid. As seen in Supplemental Figure S9, we were able to affinity-purify Spot42 in the absence of Hfq, indicating that the chaperone is not necessary for the pairing of Spot42 to $s d h C$. Together, these results indicated that expression and pairing of Spot42 to the $s d h C 5^{\prime}$ UTR led to a recruitment of Hfq. They also suggested that the Hfqbinding site located in the TIR was essential for optimal Hfq recruitment.

\section{Discussion}

Our data indicate that sRNA Spot42 binds to target mRNA $s d h C D A B$ only to recruit the RNA chaperone $\mathrm{Hfq}$, which in turn binds to a precise region of the TIR to directly inhibit translation initiation by the 30 S ribosomal subunits. This suggests a new mechanism that went against the traditional roles of the canonical model where Hfq recruits sRNA that blocks translation. In our model (Fig. 9), the function of the sRNA was only to recruit $\mathrm{Hfq}$, the major contribution of which was to block translation. Indeed, except for the pairing sequence, the specific nature of the sRNA did not seem to be of critical 
A

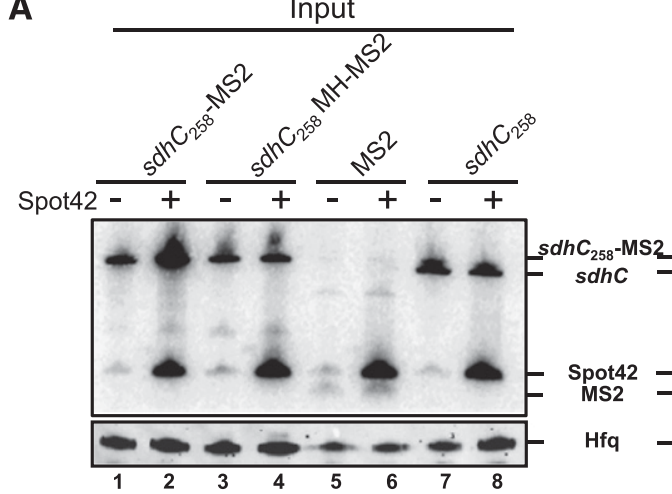

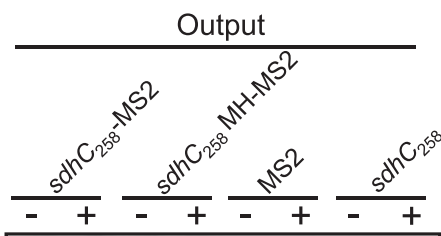

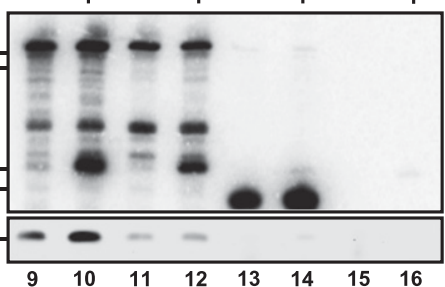

C

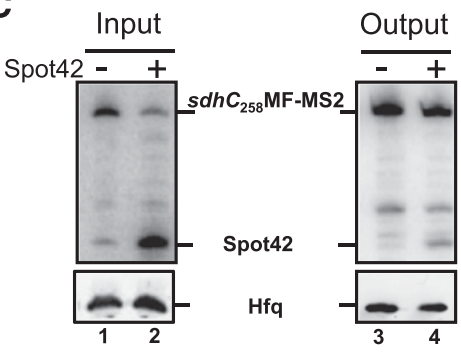

Figure 8. Spot42 binds to $s d h C D A B$ in vivo and recruits Hfq to $s d h C$ TIR. (A) Affinity purification was performed on strain EM1451 harboring pFR $\Delta-s d h C_{258}$-MS2, pFR $\Delta$-sdh $C_{258}$ MH-MS2, pFR $\Delta$-MS2, or $\mathrm{pFR} \Delta-s d h C_{258}$ in combination with pGD3 (control plasmid) or pGD3-spot42. Northern blots (MS2, sdhC, and Spot42 probes) and Western blots (Hfq antibody) were performed on samples taken before (input) and after (output) affinity purification. (B) Densitometry from the "output" signal of the level of Hfq protein relative to the levels of $s d h C_{258}$-MS2 or $s d h C_{258}$ MH-MS2 RNAs. Data are representative of three independent experiments. $(C)$ Affinity purification was performed on strain EM1451 harboring pFR $\Delta$ sdhCMF 258 -MS2 in combination with pGD3 or pGD3-spot42. Northern blots (MS2 and Spot42 probes) and Western blots (Hfq antibody) were performed on samples taken before (input) and after (output) affinity purification. importance, as we showed that Spot 42 and RyhB pairing sites could be functionally exchanged (Fig. 7). This observation suggested that sRNA pairing sites on the target mRNA, whether at the TIR (direct repression by sRNAs) or far upstream (direct repression by $\mathrm{Hfq}$ ), were key to triggering the repression mechanism of $s d h C D A B$.

In addition to Spot42, RyhB and RybB were also involved in post-transcriptional regulation of $s d h C D A B$ mRNA by directly pairing with the $5^{\prime}$ UTR of $s d h C$. Whereas RyhB and RybB directly paired with the TIR of $s d h C$, Spot 42 paired $48 \mathrm{nt}$ upstream of the start codon. Furthermore, RyhB and RybB induced the rapid turnover of $s d h C D A B$ mRNA by recruiting the RNA degradosome, but Spot 42 did not. Finally, Spot 42 absolutely required Hfq binding to an AU-rich region in the vicinity of the sdhC TIR to repress translation, but RyhB and RybB could function, at least partially, without Hfq.

Because RyhB and RybB paired directly with the SD sequence of $s d h C$, they were able to directly compete with initiating $30 \mathrm{~S}$ ribosomes. Thus, Hfq seemed not to be essential for these sRNAs to repress translation. On the other hand, because Spot 42 base-paired far upstream of the TIR, it was unable to compete directly with initiating $30 \mathrm{~S}$ ribosomes (Fig. 9A). Based on the fact that Hfq was able to compete in vitro with initiating ribosomes on $s d h C$ (Fig. 5B) and that the AU-rich site that was bound by Hfq seemed to be important for normal $s d h C$ translation in vivo (Fig. 6B), we hypothesized that the effect seen on $s d h C$ translation when Spot42 is expressed was achieved through recruitment of Hfq to the $s d h C$ TIR (Fig. 9B).

The observation that Hfq was able to repress translation by itself has been reported before (Vytvytska et al. 2000). However, to our knowledge, it is the first time that Hfq has been shown to be directly involved in 30S ribosomes competition in the context of sRNA-mediated gene regulation. Given the marked preference of Hfq for AU-rich regions and the fact that these regions are known to act as translational enhancers (Zhang and Deutscher 1992; Komarova et al. 2005; Hook-Barnard et al. 2007), we believe that Hfq may play a similar role in the action of many other sRNAs that are not pairing directly to the TIR and are therefore not able to directly compete with initiat-
A

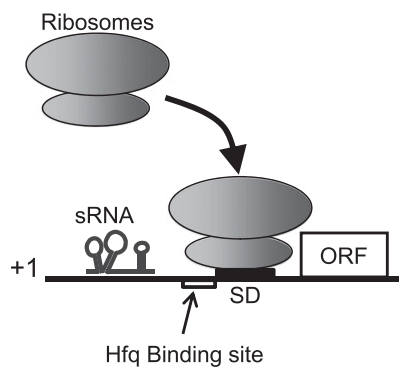

B

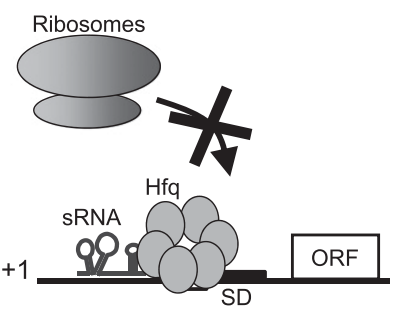

Figure 9. Working model for sRNA-mediated repression of $s d h C$ translation and the role of Hfq (see the text for details). 
ing ribosomes. Even if it was not essential for RyhB- and RybB-mediated $s d h C$ translational repression, Hfq remained involved in this regulation through roles of Hfq previously identified as being important for the stability of many sRNAs and for facilitating sRNA-mRNA pairing (Moller et al. 2002a; Zhang et al. 2002; Geissmann and Touati. 2004). Accordingly, all three sRNAs were less effective in repressing $s d h C$ translation in the $\Delta h f q$-null strain (Fig. 6B). In addition, the results (Supplemental Fig. S6) indicated that Hfq was essential for sRNA-mediated active mRNA degradation, as shown previously by other studies (Massé et al. 2003; Morita et al. 2005; Ikeda et al. 2011; Prévost et al. 2011).

The Hfq-binding site on $s d h C$ not only acted to recruit $\mathrm{Hfq}$, but also functioned as a translational enhancer. When sdhCMH was used, not only did Hfq not bind to the mRNA, but the 30 S ribosomes could bind less efficiently. In the absence of Spot42, Hfq could still bind to $s d h C$, thereby slightly reducing the initiation of translation, but with decreased efficiency.

An intriguing finding of our study was the more rapid mRNA turnover induced by sRNAs binding directly to the TIR (RyhB, RybB, and Spot42MR) than sRNAs binding far upstream of the TIR (Spot42 and RyhBMS). This observation correlated with the observed efficiency of translational repression as measured with a $\mathrm{SdhC}_{258^{-}}$ LacZ translational fusion. Indeed, whereas RyhB, RybB, and Spot42MR repressed $s d h C$ translation by at least 3.5fold (Figs. 2A, 7A), Spot42 and RyhBMS induced repression only twofold (Figs. 2A, 7A). It is possible that, contrary to RyhB or RybB, the twofold translational repression induced by Spot 42 was insufficient to induce rapid cleavage by RNase E. Interestingly, $s d h C D A B$ was not among the new Spot 42 targets recently characterized by pulse expression of Spot 42 for 15 min followed by microarray analysis (Beisel and Storz 2011). These data suggested that Spot42 as well as other well-characterized sRNAs may have more targets than those revealed solely by microarray-based data.

Whereas the $s d h C_{258}-1 a c Z$ fusion was resistant to degradation by any of the sRNAs (Fig. $2 \mathrm{~B}$ ), the full-length mRNA was not (Fig. 3A). Thus, we hypothesized that the initial cleavage site was located downstream from the 39th nucleotide of the $s d h C$ ORF. Indeed, our results suggested that the initial cleavage site on $s d h C$ mRNA following sRNA expression was located downstream from the 39th nucleotide of the ORF (Fig. 2B). This finding was reminiscent of a recent study from our laboratory (Prévost et al. 2011) that showed that RyhB induced an initial cleavage into $\operatorname{sodB}$ target mRNA $>350 \mathrm{nt}$ downstream from the pairing site.

In terms of physiological significance, it is quite remarkable that three sRNAs, each expressed under different physiological conditions, repressed the same mRNA. Because succinate dehydrogenase is a Fe-dependent enzyme, regulation by RyhB was expected, since this sRNA is expressed when Fe is not available (Massé and Gottesman 2002). With respect to Spot 42 , the only known transcription regulator is the catabolic repressor protein (CRP), which represses Spot42 expression when cAMP levels are high (Moller et al. 2002b). It has been known for some time that the expression of $s d h C D A B$ mRNA is repressed in the presence of glucose (Park et al. 1995; Takeda et al. 1999). A role for the CRP-cAMP complex in the regulation of sdhCDAB transcription has been reported (Nam et al. 2005). In addition to transcription regulation, our results suggest that Spot42 adds an additional layer of regulation that may help to increase the strength and rapidity of catabolic repression in the presence of glucose, as it was recently shown for other targets of Spot42 (Beisel and Storz 2011). Finally, the RybB sRNA has been recently characterized as a regulator of mRNAs encoding OMPs (Johansen et al. 2006; Bouvier et al. 2008; Papenfort et al. 2006, 2010). In contrast, succinate dehydrogenase is an inner membrane-located protein. RybB transcription is controlled by the alternative $\sigma$ factor $\sigma^{\mathrm{e}}$, whose activity is modulated by a signal transduction pathway (Ades 2008) induced by the recognition of a conserved YxF peptide situated in the C terminus of OMPs (Walsh et al. 2003). However, because the SdhC protein is not an OMP, it is unclear why it is involved in the $\sigma^{\mathrm{e}}$ response. Thus, the variety of signals that affect the regulation of $s d h C D A B$ mRNA—such as intracellular Fe, cAMP, and misfolded proteins-underline the importance of modulating succinate dehydrogenase according to extremely diverse environmental conditions.

\section{Materials and methods}

\section{Strains and plasmids}

Strains used in this study are listed in Supplemental Table S1. Their constructions are described in the Supplemental Material. Derivatives of EM1055 were used in all experiments. The DH5 $\alpha$ bacterial strain was used for routine cloning procedures. Cells were grown at $37^{\circ} \mathrm{C}$ in LB medium. Cells carrying pFR $\Delta$, pRS1551, and pNM12 derivatives were grown in LB medium containing ampicillin at a final concentration of $50 \mu \mathrm{g} / \mathrm{mL}$. Cells carrying pGD3 derivatives were grown in the presence of chloramphenicol at a final concentration of $30 \mu \mathrm{g} / \mathrm{mL}$.

\section{$\beta$-Galactosidase assays}

Kinetic assays for $\beta$-galactosidase activity were performed as described (Prévost et al. 2007) using a SpectraMax 250 microtitre plate reader (Molecular Devices). Briefly, overnight bacterial cultures were incubated in $\mathrm{LB}$ medium at $37^{\circ} \mathrm{C}$, diluted 1000 fold into $50 \mathrm{~mL}$ of fresh LB medium, and grown under mechanical shaking at $37^{\circ} \mathrm{C}$. sRNA expression was induced when $\mathrm{OD}_{600}$ reached a value of 0.1 by addition of arabinose to a final concentration of $0.1 \%$. Specific $\beta$-galactosidase activity was calculated using the formula $V_{\max } / \mathrm{OD}_{600}$. The results reported here correspond to data from a minimum of three independent experiments.

\section{RNA extraction and Northern blot analysis}

Total RNA was extracted using the hot-phenol procedure (Aiba et al. 1981). Cells were grown to an $\mathrm{OD}_{600}$ of 0.5 , and $0.1 \%$ arabinose was added. In the case of $s d h C$ Northern blots, $20 \mu \mathrm{g}$ of total RNA was loaded on an agarose gel $1 \%$ agarose in MOPS buffer). In the case of sRNA Northern blots, $5 \mu \mathrm{g}$ of total RNA was loaded on polyacrylamide gel (5\% acrylamide, $8 \mathrm{M}$ urea). After migration, the RNA was transferred by capillarity (agarose gel) or electro-transferred (acrylamide gel) to a Hybond-XL 
membrane (Amersham Biosciences) and UV-cross-linked. Prehybridization, hybridization, and washes were done as described (Desnoyers et al. 2009). To analyze RNA retrieved from affinity purification (below), RNA equivalent to $\mathrm{IOD}_{600}$ (input) or 18 $\mathrm{OD}_{600}$ (output) of culture were sized on polyacrylamide gels (10\% bottom $/ 5 \%$ top, $8 \mathrm{M}$ urea) and electro-transferred on a Hybond-XL membrane. Prehybridization and hybridization were done in Church buffer (Church and Gilbert 1984). DNA probes were $5^{\prime}$-end-labeled with $50 \mu \mathrm{Ci}$ of $\left[{ }^{32} \mathrm{P}\right]-\gamma$-ATP by using $\mathrm{T} 4$ polynucleotide kinase (New England Biolabs) according to the manufacturer's protocol. Oligonucleotides used as probes were sdhC (EM1696), MS2 (EM1662), and spot42 (EM1679). Washes were done in $2 \times \mathrm{SSC} / 0.1 \%$ SDS and $0.1 \times \mathrm{SSC} / 0.1 \%$ SDS. Membranes were exposed to phosphor storage screens and analyzed using a Typhoon Trio (GE Healtcare) instrument. Quantification was performed using the ImageQuant software (Molecular Dynamics).

\section{In vitro RNA synthesis and radiolabeling}

Oligonucleotides used to generate the DNA template for in vitro transcription are indicated in Supplemental Table S3. The radiolabeled probes used for Northern blot analysis were transcribed using T7 RNA polymerase (Roche) to generate the antisense transcript of the gene of interest and detection performed as described (Desnoyers et al. 2009). For the RNA used in secondary structure probing and toeprinting, transcription was performed in T7 transcription buffer, $5 \mathrm{mM}$ NTP (A, C, G, and U), $40 \mathrm{U}$ of RNaseOut (Invitrogen), $20 \mathrm{U}$ of T7 RNA polymerase, and $0.5 \mu \mathrm{g}$ of DNA templates. After $4 \mathrm{~h}$ of incubation at $37^{\circ} \mathrm{C}$, the mixture was treated with $2 \mathrm{U}$ of Turbo DNase (Ambion), extracted once with phenol-chloroform, and purified on denaturing acrylamide gel. To perform 5 '-end labeling, transcripts were dephosphorylated with calf intestine phosphatase (New England Biolabs) and $5^{\prime}$-labeled with $\left[{ }^{32} \mathrm{P}\right]-\gamma$-ATP using T4 polynucleotide kinase (New England Biolabs) according to the manufacturer's protocol. Radiolabeled transcripts were purified on denaturing acrylamide gels before use.

\section{RNA secondary structure probing}

Secondary structure probing was performed on $5^{\prime}$-end-labeled $s d h C_{258}$ or $s d h C_{258} \mathrm{MH}$ RNA (as above). Hfq was purified as described (Prévost et al. 2007). In-line probing was performed as described (Regulski and Breaker 2008). Final concentrations of $0.2 \mu \mathrm{M} s d h C_{258}$ RNA and $1 \mu \mathrm{M}$ Spot42, RyhB, or RybB were used. Lead acetate probing, ribonuclease T1/TA ladder, and alkaline $(\mathrm{OH})$ ladder were performed as described (Desnoyers et al. 2009). A final concentration of $0.2 \mu \mathrm{M} s d h C_{258}$ or $s d h C_{258} \mathrm{MH}$ RNA was used. After reactions, samples were heated for $1 \mathrm{~min}$ to $90^{\circ} \mathrm{C}$ and separated on $8 \%$ polyacrylamide/7 M urea sequencing gel.

\section{Toeprinting assays}

Toeprinting assays and $30 \mathrm{~S}$ ribosomal subunit purification were carried out as described (Fechter et al. 2009). In each condition, annealing mixture contained 2 pmol of unlabeled $s d h C_{258}$ RNA and $0.4 \mathrm{pmol}$ of 5 '-end-labeled EM1262 primer in toeprint buffer (20 mM Tris- $\mathrm{HCl}$ at $\mathrm{pH} 7.5,50 \mathrm{mM} \mathrm{KCl}, 0.1 \mathrm{mM}$ EDTA, $1 \mathrm{mM}$ DTT). Annealing mixtures were heated for $1 \mathrm{~min}$ at $90^{\circ} \mathrm{C}$ and chilled for $1 \mathrm{~min}$ on ice. $\mathrm{MgCl}_{2}$ and dNTPs were added to final concentrations of $10 \mathrm{mM}$ and $1 \mathrm{mM}$, respectively. When needed, Hfq was added, and the incubation was continued for $10 \mathrm{~min}$ at $37^{\circ} \mathrm{C}$. Spot $42, \mathrm{RyhB}, \mathrm{RybB}$, or DsrA RNA was added afterward, and the incubation was continued for $10 \mathrm{~min}$ at $37^{\circ} \mathrm{C}$. Two picomoles of $30 \mathrm{~S}$ ribosomal subunits were then added, and incubation was continued for $5 \mathrm{~min}$. Thirteen picomoles of tRNA fmet (SigmaAldrich) were added, and, 15 min later, cDNA was synthesized using SuperScript II reverse transcriptase (Invitrogen) for $15 \mathrm{~min}$ at $37^{\circ} \mathrm{C}$. Reactions were stopped, and phenol-chloroform was extracted. cDNA was ethanol-precipitated and subsequently dissolved in water and loading buffer II (Ambion). cDNA products were analyzed on $8 \%$ polyacrylamide/7M urea sequencing gel. Toeprint signals were identified by comparison with sequences generated with the same $5^{\prime}$-end-labeled primer.

\section{Affinity purification of MS2-tagged RNA}

Affinity purification assays were performed as described (Said et al. 2009), with some modifications. The MS2-MBP protein was purified as described in the Supplemental Material. The bacterial strains were grown to an $\mathrm{OD}_{600}$ of 0.5 , at which point arabinose was added to a final concentration of $0.1 \%$ to induce the expression of pBAD-RyhB, pBAD-MS2-RyhB, pBAD-MS2-RyhBLS4U, pBAD-MS2-RyhBMS-LS4U (10 min), or pGD3-spot42 (20 min). Cells equivalent to $50 \mathrm{OD}_{600}$ were chilled for $20 \mathrm{~min}$ on ice. At this point, RNA was extracted (input) as described above from $600 \mu \mathrm{L}$ of culture. The remaining cells were then centrifuged, resuspended in $1 \mathrm{~mL}$ of buffer $\mathrm{A}(20 \mathrm{mM}$ Tris- $\mathrm{HCl}$ at $\mathrm{pH} 8.0$, $150 \mathrm{mM} \mathrm{KCl}, 1 \mathrm{mM} \mathrm{MgCl} 2,1 \mathrm{mM} \mathrm{DTT}$ ), and centrifuged again. Cells were resuspended in $2 \mathrm{~mL}$ of buffer A and lysed using a French Press $(8000 \mathrm{psi}$, three times). Lysate was then cleared by centrifugation $\left(17,000 \mathrm{~g}, 30 \mathrm{~min}, 4^{\circ} \mathrm{C}\right)$. At this step, $20 \mu \mathrm{L}$ of the soluble fraction was mixed with $20 \mu \mathrm{L}$ of protein sample buffer (input). The remaining soluble fraction was subjected to affinity chromatography (all steps performed at $4^{\circ} \mathrm{C}$ ). The column was prepared by adding $75 \mu \mathrm{L}$ of amylose resin (New England Biolabs) to Bio-Spin disposable chromatography columns (Bio-Rad). The column was washed with $3 \mathrm{~mL}$ of buffer A. Next, 100 pmol of MS2-MBP protein (diluted in $1 \mathrm{~mL}$ of buffer A) was immobilized on the amylose resin, and the column was washed with $1 \mathrm{~mL}$ of buffer A. The cleared lysate was then loaded onto the column, which was washed with $5 \mathrm{~mL}$ of buffer A. RNA and proteins were eluted from the column with $900 \mu \mathrm{L}$ of buffer A containing 12 $\mathrm{mM}$ maltose. Eluted RNA was extracted with phenol-chloroform, followed by ethanol $(3 \mathrm{vol})$ precipitation of the aqueous phase in the presence of $20 \mu \mathrm{g}$ of glycogen. For protein isolation, the organic phase was subjected to acetone precipitation. RNA samples were analyzed by Northern blots as described above, and protein samples were analyzed by Western blots (below).

\section{Western blot analysis}

Proteins were resuspended in protein-loading gel electrophoresis buffer. An equivalent volume corresponding to $0.1 \mathrm{OD}_{600}$ (input) or $20 \mathrm{OD}_{600}$ (output) of cell cultures was separated on a $12 \%$ SDS-PAGE gel and transferred to nitrocellulose membrane. The anti-Hfq (kind gift of Gisela Storz, National Institutes of Health) was used at a dilution of 1:10,000. The IRDye $800 \mathrm{CW}$-conjugated goat anti-rabbit secondary antibody (Li-Cor Biosciences) was used at a dilution of 1:15,000. Western blots were revealed on an Odyssey infrared imaging system (Li-Cor Biosiences), and quantification was performed using the Odyssey software.

\section{Acknowledgments}

We thank Karine Prévost, Julie Bergeron, and Kathy Doyon for excellent technical assistance, and Gilles Dupuis for editorial comments. We thank Robert Batey (University of Colorado) for MBP-MS2 constructs. This work was funded by operating grant MOP69005 to E.M. from the Canadian Institute for Health Research (CIHR). G.D. is a PhD scholar from the FQRNT (Fonds 
Québécois de la Recherche sur la Nature et les Technologies). E.M. is a Fonds de Recherche Santé Québec (FRSQ) Junior II scholar.

\section{References}

Ades SE. 2008. Regulation by destruction: Design of the $\sigma^{\mathrm{E}}$ envelope stress response. Curr Opin Microbiol 11: 535-540.

Aiba H, Adhya S, de Crombrugghe B. 1981. Evidence for two functional gal promoters in intact Escherichia coli cells. I Biol Chem 256: 11905-11910.

Beisel CL, Storz G. 2011. The base-pairing RNA spot 42 participates in a multioutput feedforward loop to help enact catabolite repression in Escherichia coli. Mol Cell 41: 286-297.

Beyer D, Skripkin E, Wadzack J, Nierhaus KH. 1994. How the ribosome moves along the mRNA during protein synthesis. I Biol Chem 269: 30713-30717.

Bouvier M, Sharma CM, Mika F, Nierhaus KH, Vogel J. 2008. Small RNA binding to $5^{\prime}$ mRNA coding region inhibits translational initiation. Mol Cell 32: 827-837.

Church GM, Gilbert W. 1984. Genomic sequencing. Proc Natl Acad Sci 81: 1991-1995.

Darfeuille F, Unoson C, Vogel J, Wagner EG. 2007. An antisense RNA inhibits translation by competing with standby ribosomes. Mol Cell 26: 381-392.

Desnoyers G, Morissette A, Prévost K, Massé E. 2009. Small RNA-induced differential degradation of the polycistronic mRNA iscRSUA. EMBO J 28: 1551-1561.

Fechter P, Chevalier C, Yusupova G, Yusupov M, Romby P, Marzi S. 2009. Ribosomal initiation complexes probed by toeprinting and effect of trans-acting translational regulators in bacteria. Methods Mol Biol 540: 247-263.

Franze de Fernandez MT, Eoyang L, August JT. 1968. Factor fraction required for the synthesis of bacteriophage $Q \beta-R N A$. Nature 219: 588-590.

Franze de Fernandez MT, Hayward WS, August JT. 1972. Bacterial proteins required for replication of phage $\mathrm{Q}$ ribonucleic acid. Pruification and properties of host factor I, a ribonucleic acid-binding protein. J Biol Chem 247: 824-831.

Geissmann TA, Touati D. 2004. Hfq, a new chaperoning role: Binding to messenger RNA determines access for small RNA regulator. $E M B O J$ 23: 396-405.

Hajnsdorf E, Regnier P. 2000. Host factor Hfq of Escherichia coli stimulates elongation of poly(A) tails by poly(A) polymerase I. Proc Natl Acad Sci 97: 1501-1505.

Holmqvist E, Reimegard J, Sterk M, Grantcharova N, Romling U, Wagner EG. 2010. Two antisense RNAs target the transcriptional regulator CsgD to inhibit curli synthesis. EMBO J 29: 1840-1850.

Hook-Barnard IG, Brickman TJ, McIntosh MA. 2007. Identification of an AU-rich translational enhancer within the Escherichia coli fepB leader RNA. J Bacteriol 189: 4028-4037.

Huttenhofer A, Noller HF. 1994. Footprinting mRNA-ribosome complexes with chemical probes. EMBO I 13: 3892-3901.

Ikeda Y, Yagi M, Morita T, Aiba H. 2011. Hfq binding at RhlBrecognition region of $\mathrm{RNase} \mathrm{E}$ is crucial for the rapid degradation of target mRNAs mediated by sRNAs in Escherichia coli. Mol Microbiol 79: 419-432.

Jacques JF, Jang S, Prévost K, Desnoyers G, Desmarais M, Imlay J, Massé E. 2006. RyhB small RNA modulates the free intracellular iron pool and is essential for normal growth during iron limitation in Escherichia coli. Mol Microbiol 62: 1181-1190.

Johansen J, Rasmussen AA, Overgaard M, Valentin-Hansen P. 2006. Conserved small non-coding RNAs that belong to the $\sigma^{\mathrm{E}}$ regulon: Role in down-regulation of outer membrane proteins. J Mol Biol 364: 1-8.
Komarova AV, Tchufistova LS, Dreyfus M, Boni IV. 2005. AUrich sequences within $5^{\prime}$ untranslated leaders enhance translation and stabilize mRNA in Escherichia coli. I Bacteriol 187: 1344-1349.

Leroy A, Vanzo NF, Sousa S, Dreyfus M, Carpousis AJ. 2002. Function in Escherichia coli of the non-catalytic part of RNase E: Role in the degradation of ribosome-free mRNA. Mol Microbiol 45: 1231-1243.

Link TM, Valentin-Hansen P, Brennan RG. 2009. Structure of Escherichia coli Hfq bound to polyriboadenylate RNA. Proc Natl Acad Sci 106: 19292-19297.

Majdalani N, Cunning C, Sledjeski D, Elliott T, Gottesman S. 1998. DsrA RNA regulates translation of RpoS message by an anti-antisense mechanism, independent of its action as an antisilencer of transcription. Proc Natl Acad Sci 95: 1246212467.

Maki K, Uno K, Morita T, Aiba H. 2008. RNA, but not protein partners, is directly responsible for translational silencing by a bacterial Hfq-binding small RNA. Proc Natl Acad Sci 105: 10332-10337.

Massé E, Gottesman S. 2002. A small RNA regulates the expression of genes involved in iron metabolism in Escherichia coli. Proc Natl Acad Sci 99: 4620-4625.

Massé E, Escorcia FE, Gottesman S. 2003. Coupled degradation of a small regulatory RNA and its mRNA targets in Escherichia coli. Genes Dev 17: 2374-2383.

Massé E, Vanderpool CK, Gottesman S. 2005. Effect of RyhB small RNA on global iron use in Escherichia coli. J Bacteriol 187: 6962-6971.

Mohanty BK, Maples VF, Kushner SR. 2004. The Sm-like protein Hfq regulates polyadenylation dependent mRNA decay in Escherichia coli. Mol Microbiol 54: 905-920.

Moller T, Franch T, Hojrup P, Keene DR, Bachinger HP, Brennan RG, Valentin-Hansen P. 2002a. Hfq: A bacterial Sm-like protein that mediates RNA-RNA interaction. Mol Cell 9: 23-30.

Moller T, Franch T, Udesen C, Gerdes K, Valentin-Hansen P. 2002b. Spot 42 RNA mediates discoordinate expression of the E. coli galactose operon. Genes Dev 16: 1696-1706.

Morita T, Maki K, Aiba H. 2005. RNase E-based ribonucleoprotein complexes: Mechanical basis of mRNA destabilization mediated by bacterial noncoding RNAs. Genes Dev 19: 21762186.

Nam TW, Park YH, Jeong HJ, Ryu S, Seok YJ. 2005. Glucose repression of the Escherichia coli sdhCDAB operon, revisited: Regulation by the $\mathrm{CRP}^{\star}{ }^{\mathrm{c} A M P}$ complex. Nucleic Acids Res 33: 6712-6722.

Otaka H, Ishikawa H, Morita T, Aiba H. 2011. PolyU tail of rhoindependent terminator of bacterial small RNAs is essential for Hfq action. Proc Natl Acad Sci 108: 13059-13064.

Papenfort K, Pfeiffer V, Mika F, Lucchini S, Hinton JC, Vogel J. 2006. $\sigma^{\mathrm{E}}$-Dependent small RNAs of Salmonella respond to membrane stress by accelerating global omp mRNA decay. Mol Microbiol 62: 1674-1688.

Papenfort K, Bouvier M, Mika F, Sharma CM, Vogel J. 2010. Evidence for an autonomous 5' target recognition domain in an Hfq-associated small RNA. Proc Natl Acad Sci 107: 2043520440.

Park SJ, Tseng CP, Gunsalus RP. 1995. Regulation of succinate dehydrogenase (sdhCDAB) operon expression in Escherichia coli in response to carbon supply and anaerobiosis: Role of ArcA and Fnr. Mol Microbiol 15: 473-482.

Pfeiffer V, Papenfort K, Lucchini S, Hinton JC, Vogel J. 2009. Coding sequence targeting by MicC RNA reveals bacterial mRNA silencing downstream of translational initiation. Nat Struct Mol Biol 16: 840-846. 
Prévost K, Salvail H, Desnoyers G, Jacques JF, Phaneuf E, Massé E. 2007. The small RNA RyhB activates the translation of shiA mRNA encoding a permease of shikimate, a compound involved in siderophore synthesis. Mol Microbiol, 64: 12601273.

Prévost K, Desnoyers G, Jacques JF, Lavoie F, Massé E. 2011. Small RNA-induced mRNA degradation achieved through both translation block and activated cleavage. Genes Dev 25: 385-396.

Regulski EE, Breaker RR. 2008. In-line probing analysis of riboswitches. Methods Mol Biol 419: 53-67.

Rice PW, Dahlberg JE. 1982. A gene between polA and glnA retards growth of Escherichia coli when present in multiple copies: Physiological effects of the gene for spot 42 RNA. J Bacteriol 152: 1196-1210.

Said N, Rieder R, Hurwitz R, Deckert J, Urlaub H, Vogel J. 2009. In vivo expression and purification of aptamer-tagged small RNA regulators. Nucleic Acids Res 37: e133. doi: 10.1093/ nar/gkp719.

Salvail H, Lanthier-Bourbonnais P, Sobota JM, Caza M, Benjamin JA, Mendieta ME, Lepine F, Dozois CM, Imlay J, Massé E. 2010. A small RNA promotes siderophore production through transcriptional and metabolic remodeling. Proc Natl Acad Sci 107: 15223-15228.

Senear AW, Steitz JA. 1976. Site-specific interaction of $Q \beta$ host factor and ribosomal protein $\mathrm{S} 1$ with $\mathrm{Q} \beta$ and R17 bacteriophage RNAs. I Biol Chem 251: 1902-1912.

Sharma CM, Darfeuille F, Plantinga TH, Vogel J. 2007. A small RNA regulates multiple $\mathrm{ABC}$ transporter mRNAs by targeting C/A-rich elements inside and upstream of ribosomebinding sites. Genes Dev 21: 2804-2817.

Sledjeski DD, Gupta A, Gottesman S. 1996. The small RNA, DsrA, is essential for the low temperature expression of RpoS during exponential growth in Escherichia coli. EMBO I 15: 3993-4000.

Takeda S, Matsushika A, Mizuno T. 1999. Repression of the gene encoding succinate dehydrogenase in response to glucose is mediated by the EIICB $(\mathrm{Glc})$ protein in Escherichia coli. I Biochem 126: 354-360.

Tjaden B, Goodwin SS, Opdyke JA, Guillier M, Fu DX, Gottesman S, Storz G. 2006. Target prediction for small, noncoding RNAs in bacteria. Nucleic Acids Res 34: 2791-2802.

Valentin-Hansen P, Eriksen M, Udesen C. 2004. The bacterial Sm-like protein Hfq: A key player in RNA transactions. Mol Microbiol 51: 1525-1533.

Vogel J, Luisi BF. 2011. Hfq and its constellation of RNA. Nat Rev Microbiol 9: 578-589.

Vogel J, Bartels V, Tang TH, Churakov G, Slagter-Jager JG, Huttenhofer A, Wagner EG. 2003. RNomics in Escherichia coli detects new sRNA species and indicates parallel transcriptional output in bacteria. Nucleic Acids Res 31: 64356443.

Vytvytska O, Moll I, Kaberdin VR, von Gabain A, Blasi U. 2000. Hfq (HF1) stimulates ompA mRNA decay by interfering with ribosome binding. Genes Dev 14: 1109-1118.

Walsh NP, Alba BM, Bose B, Gross CA, Sauer RT. 2003. OMP peptide signals initiate the envelope-stress response by activating DegS protease via relief of inhibition mediated by its PDZ domain. Cell 113: 61-71.

Wassarman KM, Repoila F, Rosenow C, Storz G, Gottesman S. 2001. Identification of novel small RNAs using comparative genomics and microarrays. Genes Dev 15: 1637-1651.

Waters LS, Storz G. 2009. Regulatory RNAs in bacteria. Cell 136: 615-628.

Zhang J, Deutscher MP. 1992. A uridine-rich sequence required for translation of prokaryotic mRNA. Proc Natl Acad Sci 89: 2605-2609.
Zhang A, Altuvia S, Tiwari A, Argaman L, Hengge-Aronis R, Storz G. 1998. The OxyS regulatory RNA represses rpoS translation and binds the Hfq (HF-I) protein. EMBO I 17: 6061-6068.

Zhang A, Wassarman KM, Ortega J, Steven AC, Storz G. 2002. The Sm-like Hfq protein increases OxyS RNA interaction with target mRNAs. Mol Cell 9: 11-22. 


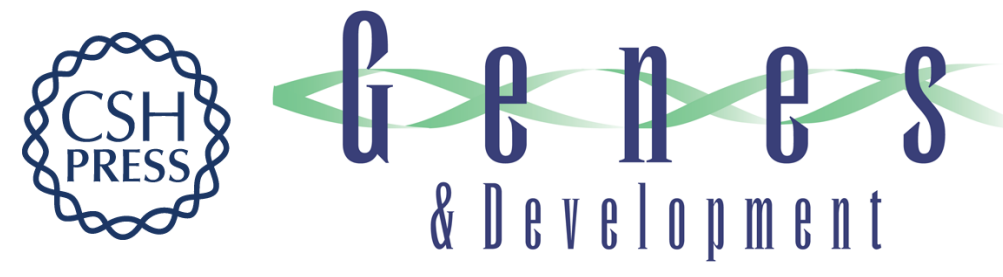

\section{Noncanonical repression of translation initiation through small RNA recruitment of the RNA chaperone $\mathrm{Hfq}$}

Guillaume Desnoyers and Eric Massé

Genes Dev. 2012, 26:

Access the most recent version at doi:10.1101/gad.182493.111

Supplemental
Material http://genesdev.cshlp.org/content/suppl/2012/03/29/26.7.726.DC1

References This article cites 58 articles, 27 of which can be accessed free at: http://genesdev.cshlp.org/content/26/7/726.full.html\#ref-list-1

License

Email Alerting Receive free email alerts when new articles cite this article - sign up in the box at the top Service right corner of the article or click here.

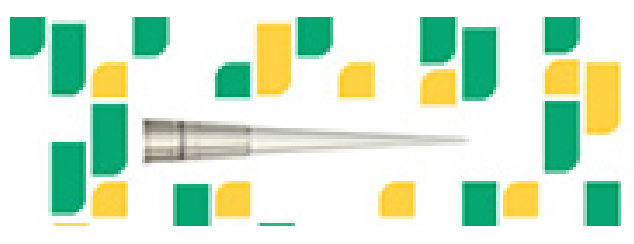

Focused on your science. 